\title{
Design of solar energy controller based on MPPT Feng-min Cheng
}

\author{
Department of Information Engineering, Tangshan College, Tangshan 063000, China \\ Email: 69670768@qq.com
}

Keywords: Solar controller; MPPT; Incremental conductance; Charge and discharge; Battery

\begin{abstract}
A solar energy controller is designed aimed at low rate of solar energy utilization, short life of battery ,circuit instability and other issues. It adopts conductance increment method to adjust the PWM control signal duty cycle, and to achieve the maximum power point tracking (MPPT)of solar energy output after the control unit analysis and calculation on the solar collecting voltage and current signals. In the battery charging and discharging process, it takes disconnect loop and connect the load to detect the end voltage of battery accurately, which effectively avoids occurrence of battery overcharge and over discharge. After the test, it proves that solar energy controller can effectively control the output of solar energy and the charge and discharge process of battery, and it ultimately improves the utilization efficiency of solar cell and prolongs the service life of battery.
\end{abstract}

\section{Introduction}

Solar energy as a new green energy, its application not only reduces the dependence on fossil fuels and reduces the greenhouse gas emissions, improves the ecological environment, but also conducive to development of low-carbon economy and realize the sustainable development of energy ${ }^{[1]}$. However, the normal work of the photovoltaic power generation systems are greatly influenced by the changes in temperature and light intensity, the price of solar cell, high efficiency and low for a long time, together with many factors, such as short service life of battery is making it difficult for the large-scale development of solar energy utilization ${ }^{[2]}$.

In order to improve the utilization efficiency of solar panel and prolong the Service life of battery, an intelligent controller is significant and is the key to realizing effective utilization of solar energy resources.

\section{Overall system design}

System consists of solar panels, battery, controller and semiconductor lighting energy load. The structure diagram is shown in figure 1.

Collecting the voltage and current at the ends of the panels through the solar panel detection circuit, charging control circuit controls the charging process of panels for battery. In order to make solar panel output efficiently, and protect the battery from overcharging, the solar charging protection module is designed.

As the voltage of battery changes constantly in charging and discharging, battery voltage sampling circuits detect the terminal voltage accurately at any moment. Charging and discharging control circuit to control the charging and discharging process, prevent the occurrence of the battery over discharge or overcharge. Two-way relay in control circuits in order to realize the charging, open the circuit and detect battery voltage, when discharge, connect the load and detect the battery voltage.

Display circuit is intuitional to understand the output current, voltage of the solar cell, the output voltage of battery and the working condition that system in. When working normally, it uses the automatic cases. We add the manual control mode, which can realize discharge and charge forcibly. 


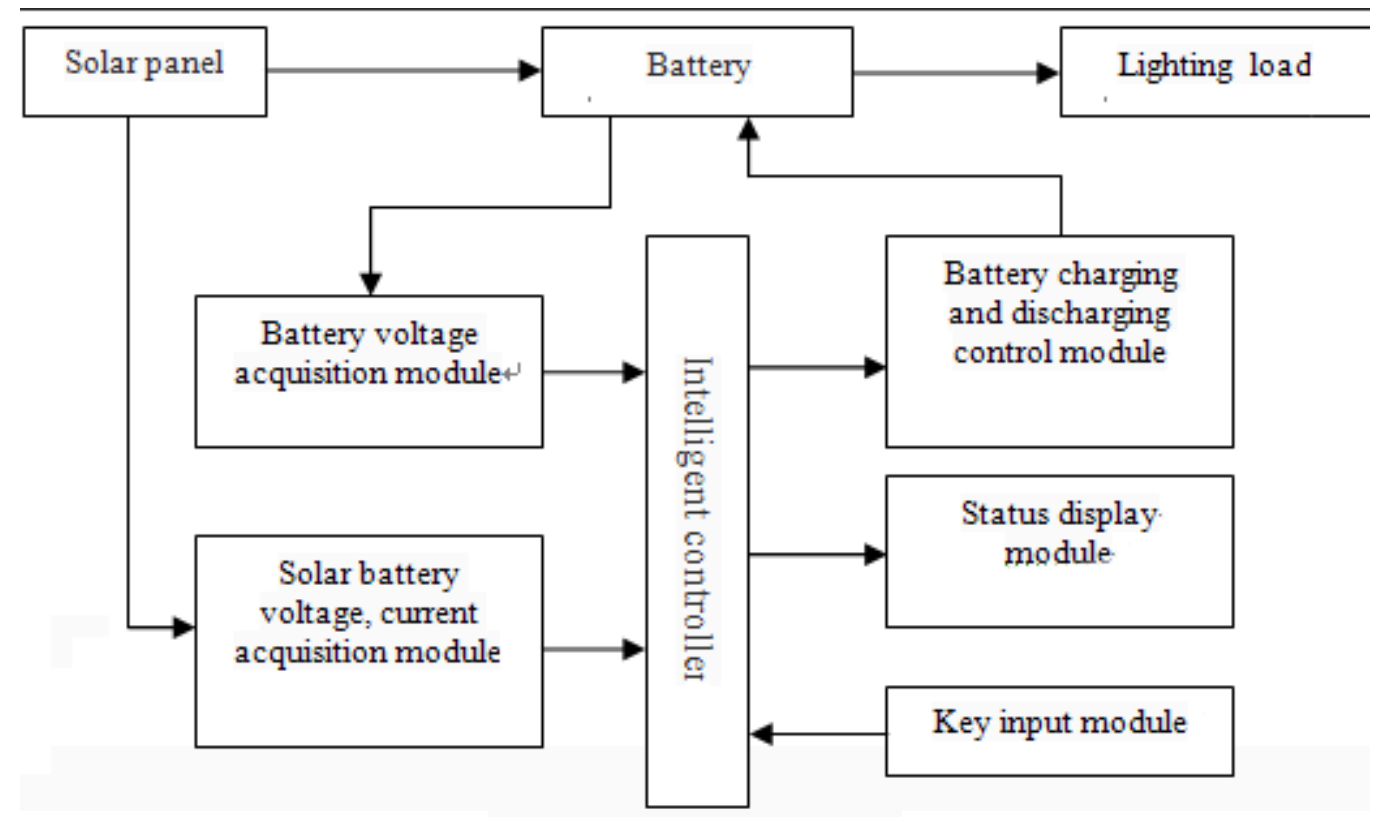

Figure 1 system diagram

\section{Module design}

\subsection{Solar energy collection circuit}

System uses solar panel of 5v.Due to the solar energy is not stable, we install Schottky diode and Zener diode inside the junction box of panels. When exerted the forward biased voltage on the both ends of Schottky barrier, the Schottky barrier layer will become narrower and its resistance will become smaller. On the contrary, if we exert reversal biased voltage on the both ends of Schottky barrier, the Schottky barrier layer will become wider, and its resistance will become larger, which can stop the current effectively ${ }^{[3]}$.

\subsection{Battery voltage acquisition circuit}

Using the hall current sensor module converting current signal to voltage signal.

While discharging, relay moving contact actuates the normally open contact, archiving the connect of batter and load, making battery supply power for load, which display collected voltage value on the LCD 1602 screen, archiving the purpose of connecting load and collecting voltage of the lithium battery. At the same time, lithium battery anode output dectricity flows through the hall current sensor, and be output voltage signal from OUT end, changing digital signal and collecting the changing current value.

While changing, relay contact closure move back to the normally closed contact, at the moment the circuit of lithium batter and load break and achieve the goal that disconnect circuit detect voltage when the battery is changing voltage.

\subsection{Charge control circuit and protection circuit}

STC12C5608AD analyzes the current and voltage values collected after power on, when charging conditions satisfied, sends out the low level, so that the coil is energized, the movable

contacts are attracted to the normally open contact, at this time the input current and output current ends of Hall current sensor module is equivalent to a wire connected the channel between the solar battery board and storage lithium battery. So that the solar battery charging

for lithium batteries .Upon detection of lithium battery charging voltage is more than $4.2 \mathrm{~V}$, Hall current sensor module's green light on, displaying the battery is saturated and stopped charging. 


\subsection{Discharge control circuit}

In order to ensure there is still part of lithium ion in carbon layer after discharge, to limit the end of discharge voltage strictly, avoid over discharge. The micro-controller on the battery terminal voltage detection analysis to determined whether voltage value is equal to the end of discharge voltage $3 \mathrm{~V}$, if it reaches the power relay coil, a moving contact reset under the action of a spring , disconnect the load ,stops supplying power to the load.

\section{Tracking algorithm of maximum power point}

Through the detection of output voltage and current of solar cell, which can calculate the maximum power point of solar panel. The maximum power point design selects the incremental conductance method to realize the tracking control of solar cells [4].

Incremental conductance method is sampled output voltage and current of solar cell. Through the calculation, comparison of the PV array instantaneous conductance and conductance increment size. Through the single-chip microcomputer control part to change the control signal. That incremental conductance method step constant avoid too small step cause working point and the maximum power point of distance and spend a lot of time to calculate. It also avoid too large step caused by the voltage oscillation increased and the power loss, reduce tracking accuracy. So the incremental conductance method with accurate control, fast response speed, to the maximum power point tracking continues stably to the output of the solar cell. The following theory control method, incremental conductance:

Through collecting solar cell output voltage $V_{\text {solar }}$ and current values $I_{\text {solar }}$, the calculated output power of solar cell:

$$
P_{\text {solar }}=V_{\text {solar }} \times I_{\text {solar }}
$$

On both sides of $\mathrm{V}$ derivative:

$$
\frac{1}{V_{\text {solar }}} \cdot \frac{d P_{\text {solar }}}{d V_{\text {solar }}}=\frac{I_{\text {solar }}}{V_{\text {solar }}}+\frac{d I_{\text {solar }}}{d V_{\text {solar }}}
$$

Let $\Delta G=-\frac{d I_{\text {solar }}}{d V_{\text {solar }}}$ as incremental conductance of solar cell, $G=\frac{I_{\text {solar }}}{V_{\text {solar }}}$

Instantaneous conductance of solar cells, type can be converted into:

$$
\frac{1}{V_{\text {solar }}} \bullet \frac{d P_{\text {solar }}}{d V_{\text {solar }}}=G-\Delta G
$$

While $\Delta G<G, \frac{d P_{\text {solar }}}{d V_{\text {solar }}}>0 ; \Delta G=G, \frac{d P_{\text {solar }}}{d V_{\text {solar }}}=0 ; \Delta G>G, \frac{d P_{\text {solar }}}{d V_{\text {solar }}}<0$.

If conductance increment is less than the instantaneous conductance , i.e. ,the instantaneous power output point of solar cell is on the left of maximum value, the output voltage of solar cell will be less than the maximum power point's ,then the output voltage value of solar cell will be increased; If conductance increment is greater than instantaneous conductance, output power point is at the right side of maximum power point ,that means solar cell's output voltage is greater than the maximum power point's , then need to reduce the output voltage of solar cell ; If conductance increment equals to the instantaneous conductance , just work at the maximum power point , then keeping the solar cell's output voltage doesn't change , now the solar cell is outputting maximum power value. Therefore Incremental Conductance is to constantly and periodically take the output voltage and current of solar cell, then use above formula to calculate, finally find out the voltage value at which the conductance increment equals to the instantaneous conductance, which is corresponding to the maximum power point [5] .

\section{Conclusions}

Display the solar output voltage, output current and voltage values of the battery in real time via 
the LCD screen, we could judge the remaining battery capacity. When there is insufficient battery capacity continues to discharge, the discharge can be manually controlled stop. The system also sets the button control module to increase manual control function that can be achieved manually forced charging and discharging functions.

\section{References}

[1] Guoyi Wang. Research of Photovoltaic Lighting System Intelligent Controller [D].Anhui Engineering University, June 2012:20-25

[2] Wei Chen.Solar Photovoltaic Applications in Energy Storage Systems Research [D].Chin a Technology University, May 2005:31-34

[3] Ruixia Jia,Lijuan Wang. Solar LED Street Light Controller Based on MCU [J].Zhengzho u Watson Institutes, September 2013:47-50

[4] Hongxing Jiang.Solar Lighting System Controller Design and Battery Health Check [D]. Shandong University, May 2011:8-59

[5] Tianshi Zhang.Solar Lighting Energy Management and PSoC Design [D]. Changchun Te chnology University, March 2013:5-15 